\title{
Case report on xeroderma pigmentosum with squamous cell carcinoma in a ten year old child
}

\section{Uday Kumar Sonnappa, Aneesh Samayam}

\author{
Department of Dermatology MVJ Medical College and Research Hospital, Hoskote Bangalore, India
}

Corresponding author: Dr. Uday Kumar Sonnappa, E-mail: udnvab@gmail.com

\begin{abstract}
Xeroderma pigmentosum (XP)is a rare inherited skin disorder characterized by a heightened sensitivity to the DNA damaging effects of ultraviolet radiation (UV). The main source of UV is the sun. The symptoms of XP can be seen in any sun-exposed area of the body. The effects are greatest on the skin, the eyelids and the surface of the eyes but the tip of the tongue may also be damaged. In addition, approximately $25 \%$ of XP patients also develop abnormalities of the nervous system manifesting as progressive neuro-degeneration with hearing loss. People with XP have a 10,000fold increased risk for developing skin cancer including basal cell carcinoma, squamous cell carcinoma and melanoma. They also have a 2000-fold increased risk for cancer of the eye and surrounding ocular tissues. These symptoms appear early in life, typically before age 10 years. This case is being presented to highlight the rarity of a case of xeroderma pigmentosum with squamous cell carcinoma in a ten year old child.
\end{abstract}

Key words: Xeroderma pigmentosum; Squamous cell carcinoma in a child; Carcinoma

\section{INTRODUCTION}

Xeroderma pigmentosum (XP) was first described in 1874 by Hebra and Kaposi. In 1882, Kaposi coined the term xeroderma pigmentosum for the condition, referring to the characteristic dry, pigmented skin seen in these patients [1,2]. XP is a genodermatosis characterized by photosensitivity, cutaneous pigmentary changes, premature skin aging and the development of cutaneous and internal malignancies at an early age. These patients exhibit enhanced sensitivity to ionizing radiation $[1,3,4]$.

\section{CASE REPORT}

A ten year old child born of a second degree consanguinity Presented to the Dermatology OPD at MVJMC \& RH with Complaints of. Difficulty in opening eyes to broad day light since six months of age. Multiple dark and pale coloured discolouration present all over the body predominantly over sun exposed area. Swelling arising from the right eye since four months, associated with redness and watery discharge from both the eyes.
Patient was apparently normal at birth later cried excessively on bring out to the sun since six months of age. Patient would also refuse to open her eyes as a child to broad day light since six months of age. Patient also complaints of multiple dark and pale coloured discolouratioin associated with scales being present diffusely. Predominantly over the sun exposed area first starting over the face. Complaints of a swelling arising from the right lower eyelid since four months, which was insidious in onset initially of the size of a pea, which gradually progressed over a duration of three months to attain the present size of approximately $2 \times 3 \mathrm{~cm}$.

No H/o of application of native medicine. No H/o trauma to the eye. No H/o of known allergy to food, drug.

\section{Family History}

The Patient is a second child born to second degree consanguineous marriage.

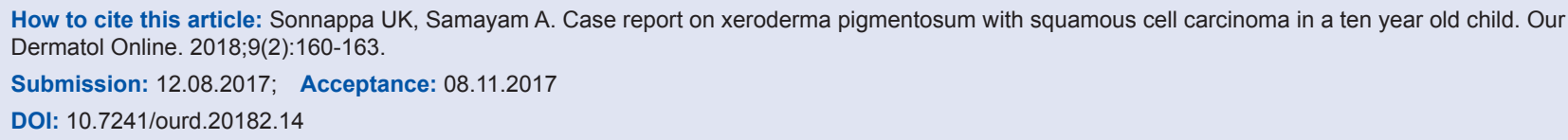




\section{Birth History}

FTVD.

\section{Developmental History}

Attained developmental milestones.

\section{Immunization History}

Received as per schedule.

\section{General Physical Examination}

A moderately built and moderately nourished child who is consious and co-operative, Well oriented to time place and person.

\section{Vitals}

Normal.

\section{On Examination}

Extensive erosions with haemorrhagic crusts over the face, diffuse freckling, atrophic hyper and hypopigmented macules, ciliary and conjunctival congestion associated with watery discharge from bilateral eyes (Figs. 1-3).

A ulcero proliferative growth of size $3 \times 4 \mathrm{~cm}$ arising from the lateral aspect of right lower eyelid, the swelling is immobile, tender firm to hard in consistency. Eyelashes partially destroyed over b/l eyes. Systemic examination within normal limits.

With this we arrived a provisional diagnosis of xeroderma pigmentosus with squamous cell carcinoma.

\section{Management}

Initally patient was started on systemic and topical antibiotics analgesics and sunprotection. For further management patient was referred to ophthalmologist and plastic surgeon. Ophthalmologist prescribed tear drops, homatropine eye drops, antibiotic eye drops. Plastic surgeon did a wedge excision of the growth under local anaesthesia and specimen was sent for biopsy, which revealed well differentiated squamous cell carcinoma (Fig. 4).

\section{Histopathology Report}

Growth showed well differentiated squamous cell carcinoma - right eye lid and cheek (Figs. 5 and 6).

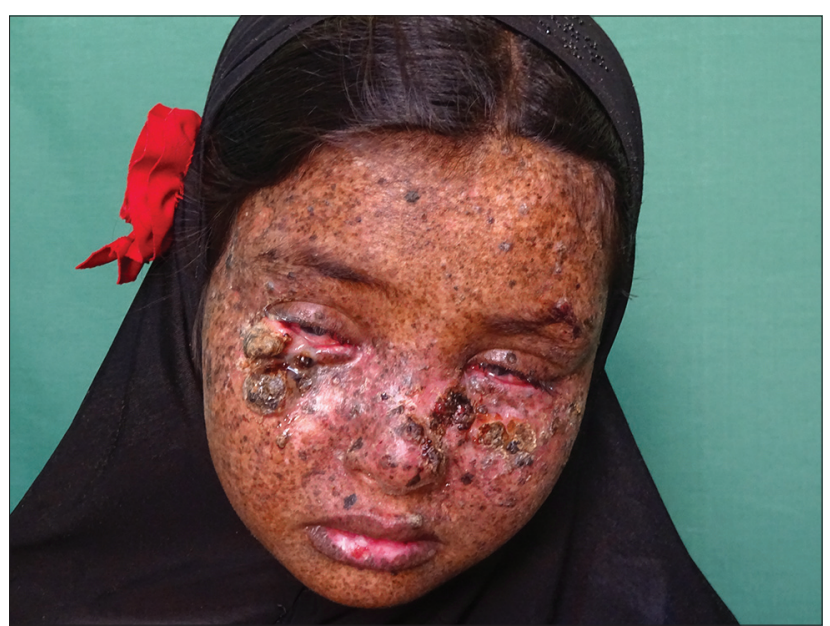

Figure 1: A single ulceroproliferative lesion arising from the lateral aspect of right lower eyelid.

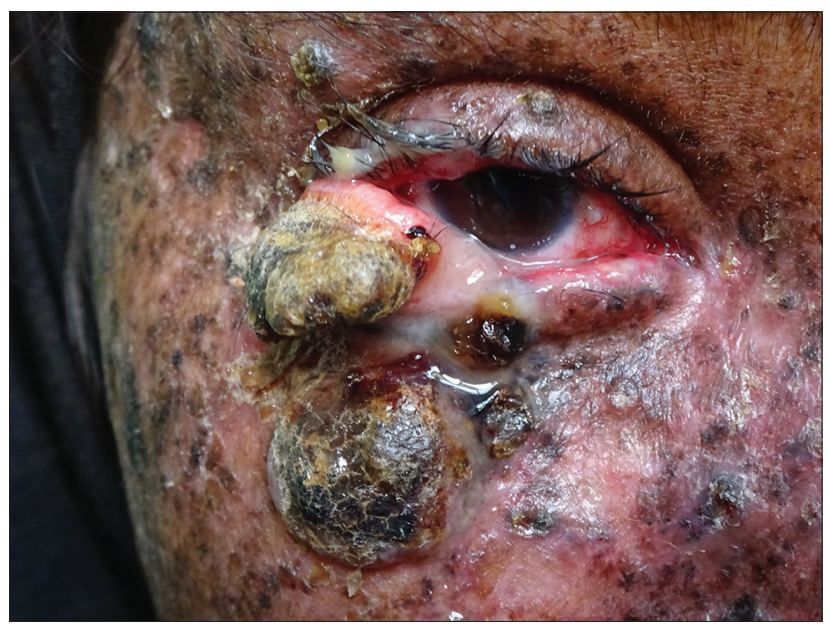

Figure 2: Haemorrhagic crusts over the face, diffuse freckling, atrophic hyper and hypopigmented macules and ciliary and conjunctival conjestion.

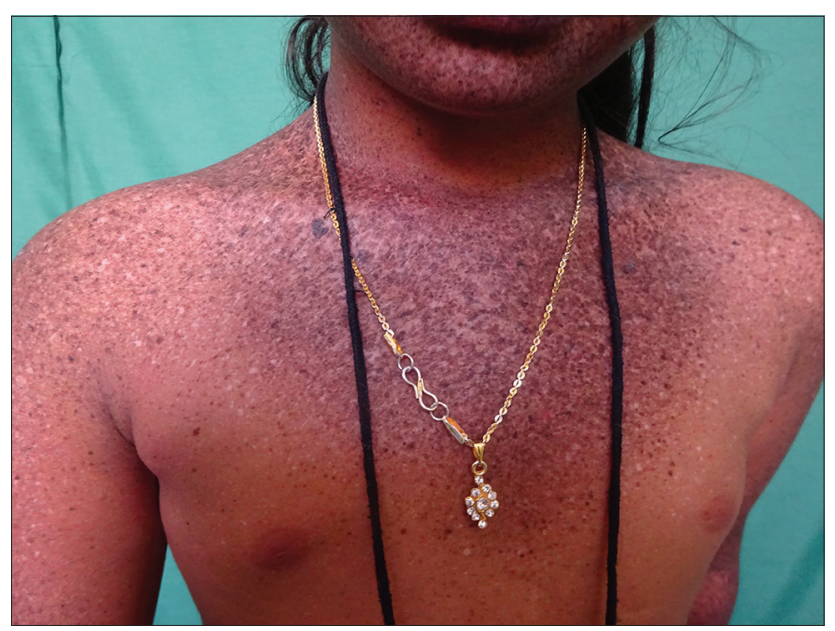

Figure 3: Atrophic hyper and hypopigmented macules.

Superolateral and superomedial margins are involved by tumour, with staging $\mathrm{PT}_{2} \mathrm{~N}_{\mathrm{x}} \mathrm{M}_{\mathrm{x}}$. 


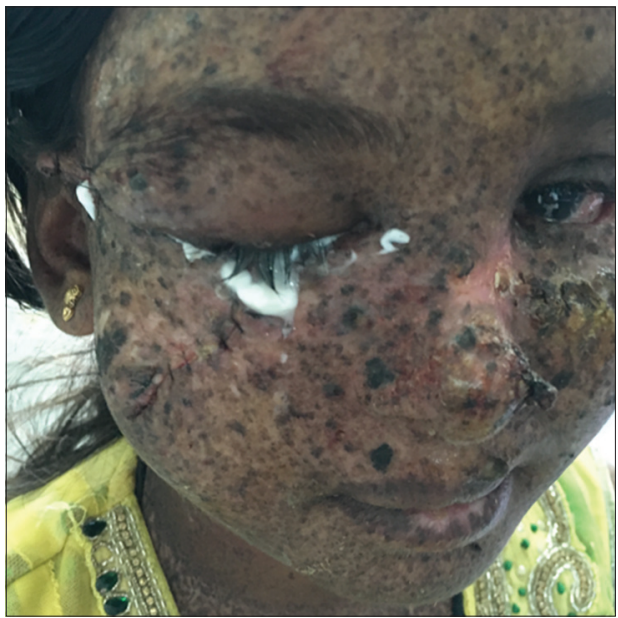

Figure 4: Post excision picture of the ulcero-proliferative lesion on histopathological examination revealed squamous cell carcinoma.

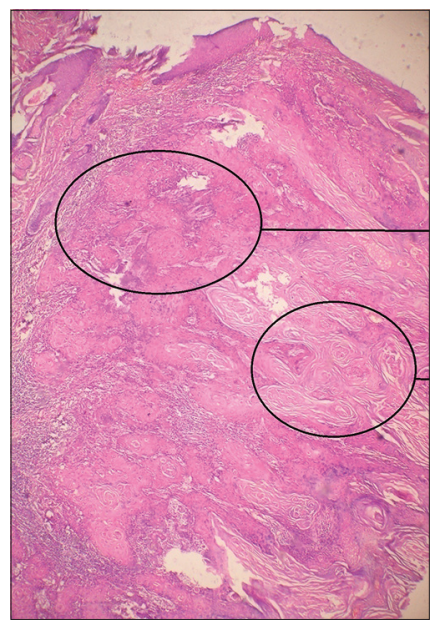

Figure 5: Epidermis and dermis, irregular rete ridges extending to dermis and atypicalcells. With well differentiated squamous cells, HPE:10X. In the order top to bottom: $1^{\text {st }}$ arrow: well differentiated nests of malignant squamous epithelial cells. $2^{\text {nd }}$ arrow: keratin pearls.

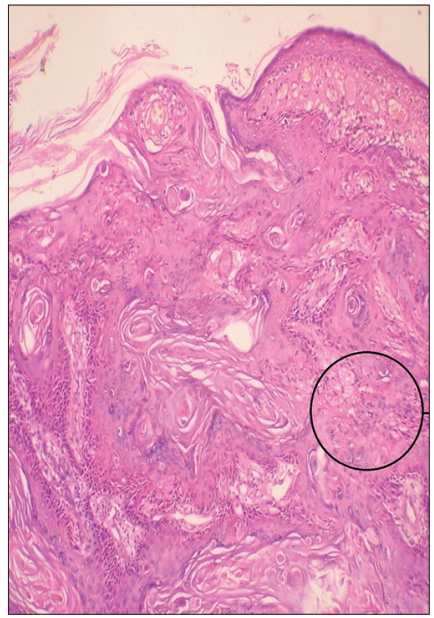

Figure 6: Epidermis and dermis, irregular rete ridges extending to dermis and atypicalcells. Chronic inflammatory cells composed of lymphocytes is seen, HPE:10X. Arrow: Chronic inflammatory cells composed of lymphocytes.
Thus the final diagnosis of xeroderma pigmentosus with squamous cell carcinoma was made.

\section{DISCUSSION}

$\mathrm{XP}$ is inherited as an autosomal recessive trait. It is a rare pigmentary atrophic disease that begins in childhood and progresses to early development of senile changes in sun-exposed skin [5]. Parental consanguinity is common. $\mathrm{XP}$ occurs with an estimated frequency of 1:250000 in the US and, according to Robbins et al., is more common in Japan. The incidence in the Indian population is insignificant. XP shows no sex preference $[1,3,6]$.

The basic defect in XP is in Nucleotide excision repair, leading to deficient repair of DNA damaged by UV radiation. NER involves removal and the replacement of damaged DNA with new DNA. Two types of NER exist: global genome NER (GG-NER) and transcription-coupled NER (TC-NER). In addition to defects in the NER genes the immunosuppressive effects of UV-B radiation may also be involved in the pathogenesis of XP.

XP patients below 20 years of age have a $>1000$-fold increased risk of developing skin cancer [6,7]. The median age of onset of non-melanoma skin cancers reported in patients with $\mathrm{XP}$ is 8 years, compared to 60 years in the healthy population. Variations in the type of malignancies in XP appear to be related to the degree of sun exposure and genetic heterogeneity [8]. The two most common types of cancer found in XP patients are BCC and SCC, mainly occurring on the face, head, and neck. Melanomas occur in one-fourth of cases, and one-third of these occur in the head and neck [4]. Early detection of these malignancies is necessary because they are fast growing, metastasize early and lead to death. Two important causes of mortality are metastatic melanoma and SCC.

Most patients with XP do not live beyond the third decade because of the development of tumors [4]. Cutaneous neoplasms in XP patients cannot be prevented but early protection from UV radiation should be advised. Premalignant skin lesions may be treated with cryosurgery or topical antimitotic agents. Early removal of neoplasms should be accomplished with excision, chemosurgery or intralesional IFN- $\alpha$. In selected XP patients, oral isoretinoin has been shown to significantly reduce the incidence of skin cancers [9].

A recent clinical trial by Yarosh et al. [10] found that 
the enzyme T4 endonuclease V, applied regularly as a topical agent, significantly reduced the onset of both BCC and actinic keratoses, thus giving a little hope to XP patients, who suffer from much psychological trauma and face many socioeconomic problems. Although, early detection and treatment of cutaneous malignancies will reduce morbidity and mortality, genetic counseling remains the most important measure for preventing XP.

\section{CONCLUSION}

This case is being presented to highlight the rarity of a case of xeroderma pigmentosum with squamous cell carcinoma in a ten year old child. And need for early diagnosis and prompt treatment.

\section{REFERENCES}

1. Rao TN, Bhgyalaxmi A, Ahmed K, MohanaRao TS, Venkatachalam K. A case of melanoma in xeroderma pigmentosum. Indian J Pathol Microbiol. 2009;52:524-6.

2. Pradhan E, Padhye SB, Malla OK, Karki KJD. Case of xeroderma pigmentosum with well differentiated squamous cell carcinoma in the eye. Kathmandu Univ Med J (KUMJ). 2003;1:278-83.

3. Arora R, Sharma A, Gupta R, Vijayraghavan M. Cutaneous angiosarcoma in a patient with xeroderma pigmentosum. Indian J Pathol Microbiol. 2008;51:504-6.

4. Alymlahi E, Dafiri R. Bilateral facial squamous cell carcinoma in an 18-month-old girl with xeroderma pigmentosum. J Postgrad Med. 2005;51:128-30.

5. Kocabalkan O, Ozgur F, Erk Y, Gursu KG, Gungen Y. Malignant melanoma in xeroderma pigmentosum patients: Report of five cases. Eur J Surg Oncol. 1997;23:43-7.

6. Mohanty P, Mohanty L, Devi BP. Multiple cutaneous malignancies in xeroderma pigmentosum. Indian J Dermatol Venereol Leprol. 2001;67:96-7.

7. Patil MR, Vishwanath V, Arya M, Shenoy BP, Bharmal RN, Torsekar RG. Pilomatricoma in a case of familial xeroderma pigmentosum. Indian J Dermatol Venereol Leprol. 2007;73:198-9.

8. Itin HP, Burgdorf WH, Happle R, Paller A, Konig A, Pierini A, et al. Genodermatoses. In: Schaner LA, Hansen RC, editors. Pediatric Dermatology. $3^{\text {rd }}$ ed. Mosby: Elsevier Limited; 2003. p. 328-32.

9. DiGiavanna JJ. Retinoid chemoprevention in patients at high risk for skin cancer. Med Pediatr Oncol. 2001;36:564-7.

10. Yarosh D, Klein J, O'Connor A, Hawk J, Rafal E, Wolf P. Effect of topically applied $\mathrm{T} 4$ endonuclease $\mathrm{V}$ in liposomes on skin cancer in xeroderma pigmentosum: A randomized study. Xeroderma Pigmentosum Study Group. Lancet. 2001;357:926-9.

Copyright by Uday Kumar Sonnappa, et al. This is an open-access article distributed under the terms of the Creative Commons Attribution License, which permits unrestricted use, distribution, and reproduction in any medium, provided the original author and source are credited. Source of Support: Nil, Conflict of Interest: None declared. 